\title{
HIGH PERFORMANCE OF ELECTROACOUSTIC PIEZOELECTRIC CERAMIC TRANSDUCERS
}

\author{
M.I. AbD El-Ati ${ }^{a}$, M.M. MosaAd ${ }^{b}$ AND B.Y. El-Baradie ${ }^{a}$ \\ ${ }^{a}$ Physics Department, Faculty of Science, Tanta University, Tanta, Egypt \\ ${ }^{b}$ Physics Department, Faculty of Education, Kafr El-Sheikh, Egypt
}

(Received December 3, 1991; revised version March 6, 1992)

\begin{abstract}
Lead zirconate-titanate containing 1 wt \% niobium with different $\mathrm{Zr} / \mathrm{Ti}$ ratios compositions were studied. A pronounced increase in densification during sintering process occurred near tetragonal-rhombohedral phase. Dielectric constant of polarized and unpolarized samples was studied. The rotation of all $90^{\circ}$ domains to their original positions caused the more looseness of $\mathrm{Ti}^{4+}$ and $\mathrm{Zr}^{4+}$ in the octahedral configuration leading to greater polarization in the tetragonal structure, thus leading to higher dielectric constant. Near the phase change, the minimum resonance frequency caused the minimum values of ultrasonic waves, which were emitted from the edge of the polarized ceramic transducers.
\end{abstract}

PACS numbers: $43.35 .+\mathrm{d}, 77.60 .+\mathrm{v}$

\section{Introduction}

Ceramic compositions have widely different piezoelectric constants and, thercfore, provide different mechanical or acoustic amplitude at a given electric field [1]. The origin of nonlinear behaviour of lead zirconate-titanate (ferroelectric hysteresis loop) lies in domain reorientation.

In general, there are two types of domain switching possible, either by $180^{\circ}$ or by discrete angles other than $180^{\circ}$ (switching of the latter type is by $90^{\circ}$ in tetragonal perovskites, by $71^{\circ}-109^{\circ}$ in rhombohedral perovskites, and by $90^{\circ}$ or $60^{\circ}-120^{\circ}$ in orthorhombic perovskites). Electric fields may cause the domain switching of either type in a virgin material, but the domain switching of the first type is predominant in a poled material. Mechanical stress can cause only domain switching of the second type whether the specimen is poled or not [2-9]. The effect of doping with tri- and pentavalent ions on the Young's modulus and piezoelectric properties near the morphotropic boundary produced high-quality piezoelectric ceramic transducers. In the previous. work [10], the sound wave velocity of the ceramic resonator at resonance was estimated. 
The aim of the present work is to study a new lead zirconate-titanate ceramic of a composition $\mathrm{Pb}\left(\mathrm{Zr}_{x} \mathrm{Ti}_{1-x}\right) \mathrm{O}_{3}$ by changing the ratio of $\mathrm{Zr} / \mathrm{Ti}$, in order to determine Young's modulus and dielectric constant of the samples.

\section{Experimental procedure}

Lead zirconate-titanate ceramics were sintered at about $1300^{\circ} \mathrm{C}$ for $2 \mathrm{~h}$ from the mixture of $\mathrm{PbZrO}_{3}$ and $\mathrm{PbTiO}_{3}$ in an ordinary way playing with the ratio of $\mathrm{Zr} / \mathrm{Ti}$ before the sintering process. X-ray diffraction pattern confirm our composition.

The two opposite faces of each disk were painted with silver paste. Electrical capacitance was measured with RLC bridge, type TESLA Bron, BM 591 (Czecho-Slovakia) at $1 \mathrm{kHz}$. Measurements were taken at room temperature $\left(25^{\circ} \mathrm{C}\right)$. Poling was carried out in silicon oil at $100^{\circ} \mathrm{C}$ under an applied field of $10^{6} \mathrm{~V} / \mathrm{m}$. The sample was then cooled to room temperature with the field maintained.

The bulk density $\rho\left[\mathrm{kg} / \mathrm{m}^{3}\right]$ of the sintered samples was measured by a method very similar to that previously described by Tawfik et al. [5].

The resonance frequency $f_{\mathbf{r}}$ of the radial mode was measured for each composition by a method very similar to that of Ref. [6].

\section{Results}

\subsection{Effect of $\mathrm{Zr} / \mathrm{Ti}$ ratio on the density of $\mathrm{Pb}\left(Z r_{x} \mathrm{Ti}_{1-x}\right) \mathrm{O}_{3}$ ceramic containing 1 wt \% niobium}

Figure 1, curve $a$, represents the increase in the density of $\mathrm{Pb}\left(\mathrm{Zr}_{x} \mathrm{Ti}_{1-x}\right) \mathrm{O}_{3}$ (PZT) containing 1 wt \% niobium ceramic compositions with increasing $\mathrm{Zr} / \mathrm{Ti}$ ratio. To attain the optimum value at the ratio $\mathrm{Zr} / \mathrm{Ti}=0.54 / 0.46$, which is the critical composition, where the crystal structure is tetragonal, above this ratio the ceramic composition is transferred to the rhombohedral structure.

In the tetragonal structure of the composition below the ratio $\mathrm{Zr} / \mathrm{Ti}=$ $0.54 / 0.46$, the increase in density with increasing $\mathrm{Zr} / \mathrm{Ti}$ ratio is attributed to the increase in the atomic weight of zirconium ions with respect to that of titanium ions in the composition, leading to the increase in density during the sintering of the samples. In the rhombohedral structure $(\mathrm{Zr} / \mathrm{Ti}>0.54 / 0.46)$, the formation of excess cation vacancies $\left(\mathrm{Pb}^{2+}\right.$ vacancies) reduces the concentration of anion (oxygen) vacancies which results in a decrease in oxygen ion diffusion and sintering rate.

\subsection{Dependence of resonance frequency on the $Z r / T i$ ratio}

In figure 1 , curve $b$ represents the variation of resonance frequency with the variation of $\mathrm{Zr} / \mathrm{Ti}$ ratio of $\mathrm{PZT}$ containing $1 \mathrm{wt} \%$ niobium resonator. From the results, it can be noticed that the decrease in the resonance frequency of the polarized ceramic resonator is attributed to the reduction of porosity in the tetragonal phase as indicated by curve $a$ in Fig. 1 . The polarized tetragonal phase includes 


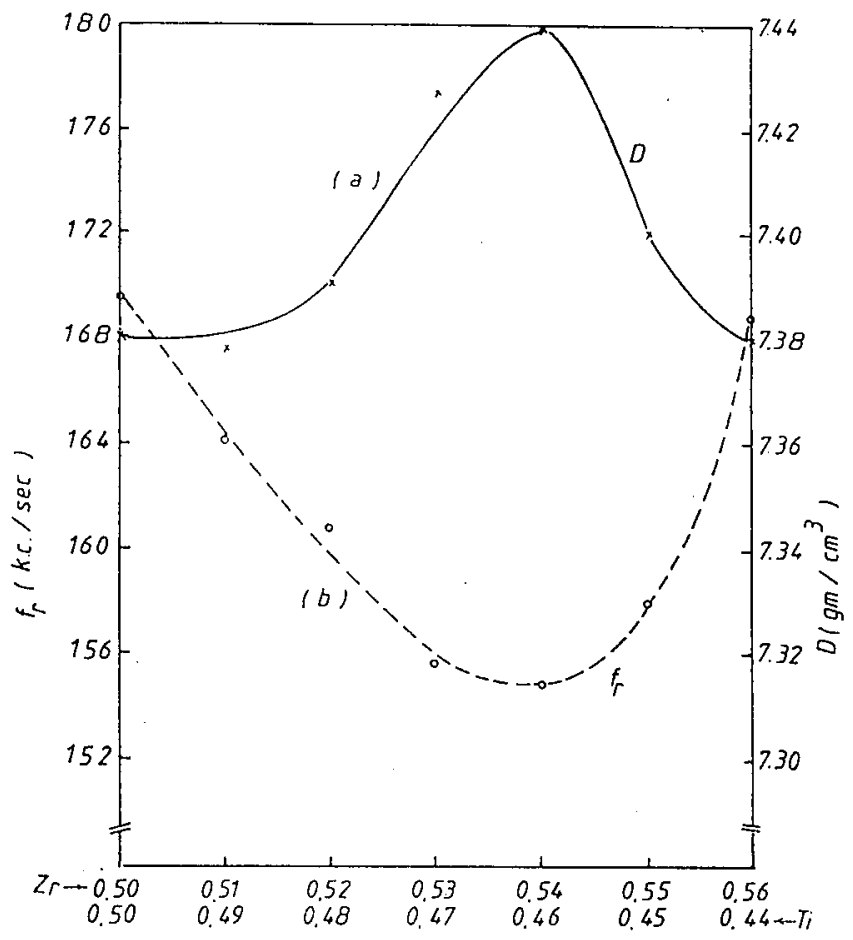

Fig. 1. $a-$ Effect of $\mathrm{Zr} / \mathrm{Ti}$ ratio on the density of $\mathrm{Pb}\left(\mathrm{Zr}_{x} \mathrm{Ti}_{1-x}\right) \mathrm{O}_{3}$ ceramic containing 1 wt \% niobium. $b$ - Dependence of resonance frequency on the $\mathrm{Zr} / \mathrm{Ti}$ ratio.

two types of domains, the $180^{\circ}$ domains and $90^{\circ}$ domains. All the reversal $180^{\circ}$ domains remain entire after poling process and small percentage of $90^{\circ}$ domains is maintained after the process. The increase in density with $\mathrm{Zr} / \mathrm{Ti}$ ratio increased the number of $180^{\circ}$ domains and more proportion of $90^{\circ}$ domains, leading to more piezoelectric interaction between the crystallites. This interaction encourages the ions to oscillate at lower frequency with increasing dipole moment. This explains the lowering of the resonance frequency in the tetragonal structure of the resonator.

In the rhombohedral structure, there are three types of domains, $180^{\circ}, 109^{\circ}$ and $71^{\circ}$ domains. The remains of some proportion of $71^{\circ}$ and $109^{\circ}$ domains after poling process gave rise to more internal strain which caused the ions to oscillate at higher frequency. In our conclusion the best composition for application work to obtain high energy of ultrasonic wave is the rhombohedral structure of piezoelectric transducers.

\subsection{Effect of variation of $Z r / T i$ ratio on the velocity of ultrasonic wave in PZT transducer}

Figure 2 represents the effect of increasing zirconium in PZT composition on the velocity of ultrasonic wave generated from the PZT transducer containing 1 wt \% niobium. The decrease in the velocity of the ultrasonic wave with 


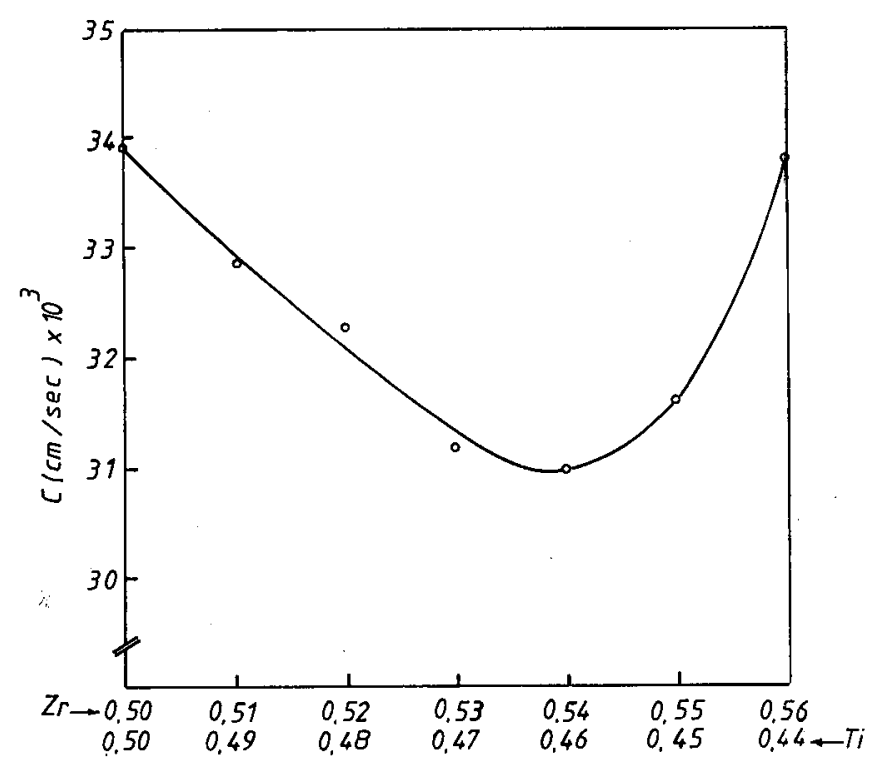

Fig. 2. Variation of $\mathrm{Zr} / \mathrm{Ti}$ ratio with the velocity of ultrasonic wave in PZT transducer.

increasing zirconium is attributed to the greater piezoelectric coupling between the constituent ions. The increase in density in this tetragonal structure increases the dipole moment per unit volume, leading to more looseness. The increase in the looseness of titanium ions of smaller radius in the perovskite structure helps the titanium ions to oscillate at lower frequency with the external applied field. This explanation confirms the decrease in the velocity of the wave in the polarized PZT transducers of perovskite structure.

For the composition containing $\mathrm{Zr} / \mathrm{Ti}>0.54 / 0.46$, it is noticed that the density of the different compositions decreased with increasing $\mathrm{Zr} / \mathrm{Ti}$ in the rhombohedral structure. After poling process, the piezoelectric interaction between the dipoles decreased due to the decrease in the number of ions per unit volume. The less dipole moment per unit volume caused the less piezoelectric interaction leading to higher frequency of vibration.

From our results, one can conclude that high velocity of ultrasonic wave can be obtained from polarized PZT containing $1 \mathrm{wt} \%$ niobium in the rhombohedral structure.

\subsection{Variation of Young's modulus with $Z r / T i$ ratio of the PZT}

Figure 3 shows the decrease in Young's modulus with the increase in $\mathrm{Zr} / \mathrm{Ti}$ ratio (tetragonal state). For $\mathrm{Zr} / \mathrm{Ti}>0.54 / 0.46$ (rhombohedral structure), Young's modulus increases with increasing percentage of zirconium.

It might be expected that doping with more percentage of $\mathrm{Zr}$ of higher atomic weight than in $\mathrm{Ti}$ atom (forming additional oxygen vacancies) would increase the rate of diffusion and densification. 


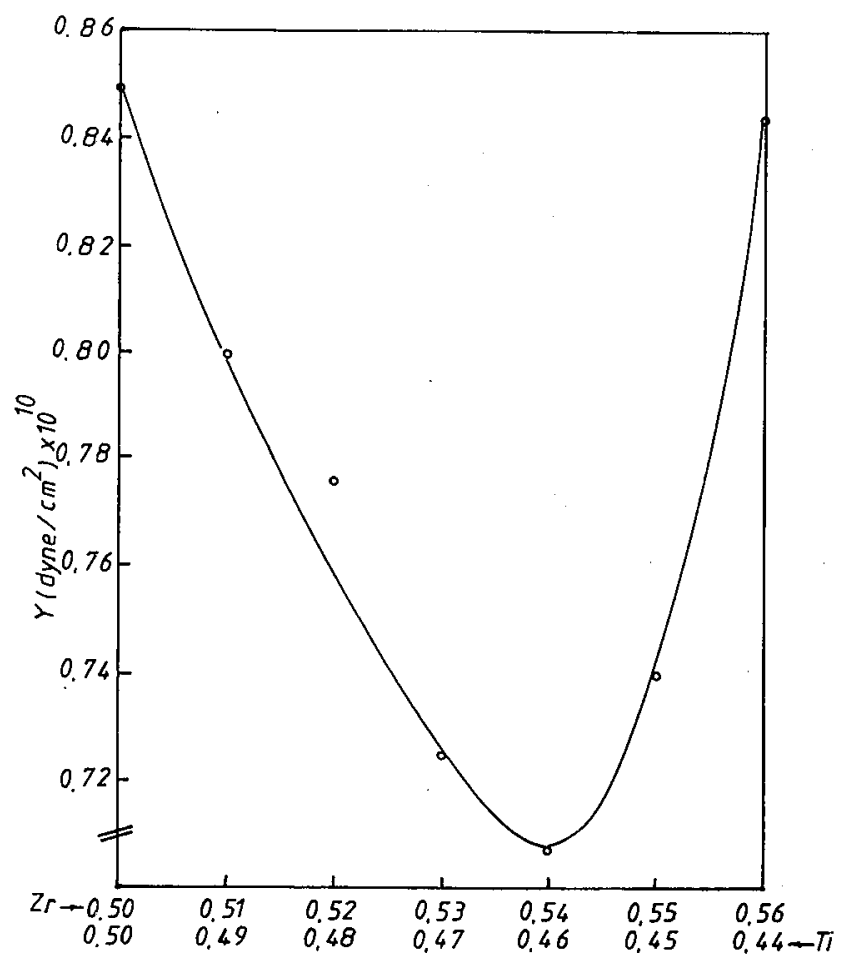

Fig. 3. Variation of Young's modulus with Zr/Ti ratio of the PZT.

The existence of three types of domains in the rhombohedral structure $\left(180^{\circ}\right.$, $109^{\circ}$ and $71^{\circ}$ domains) leads to the increase in the dipole moment of the structure with respect to that of the tetragonal structure of two types of domains $\left(180^{\circ}\right.$, $90^{\circ}$ ) [11]. The increase in the dipole moment helped the domain wall to interact easily at lower frequency of the applied a.c. field. The lowering of the resonance frequency of the rhombohedral structure of the resonator caused the decrease of Young's modulus [12].

\subsection{Effect of $Z r / T i$ ratio on the dielectric constant} of polarized and unpolarized PZT containing $1 \mathrm{wt} \%$ niobium

Figure 4 represents the dielectric constant of polarized and unpolarized samples of PZT having different $\mathrm{Zr} / \mathrm{Ti}$ ratios. From the figure, it can be seen that the dielectric constant of polarized and unpolarized samples increased with increasing $\mathrm{Zr} / \mathrm{Ti}$ ratios.

The increase in the dielectric constant in the tetragonal structure of the composition is due to the phase transition of the crystal structure from tetragonal to rhombohedral phase. In the rhombohedral structure, the decrease in the dielectric constant is due to the decrease in the looseness of $\mathrm{Zr}^{4+}$ ions in the octahedral configuration, because the ionic radius of zirconium is larger than the ionic radius 


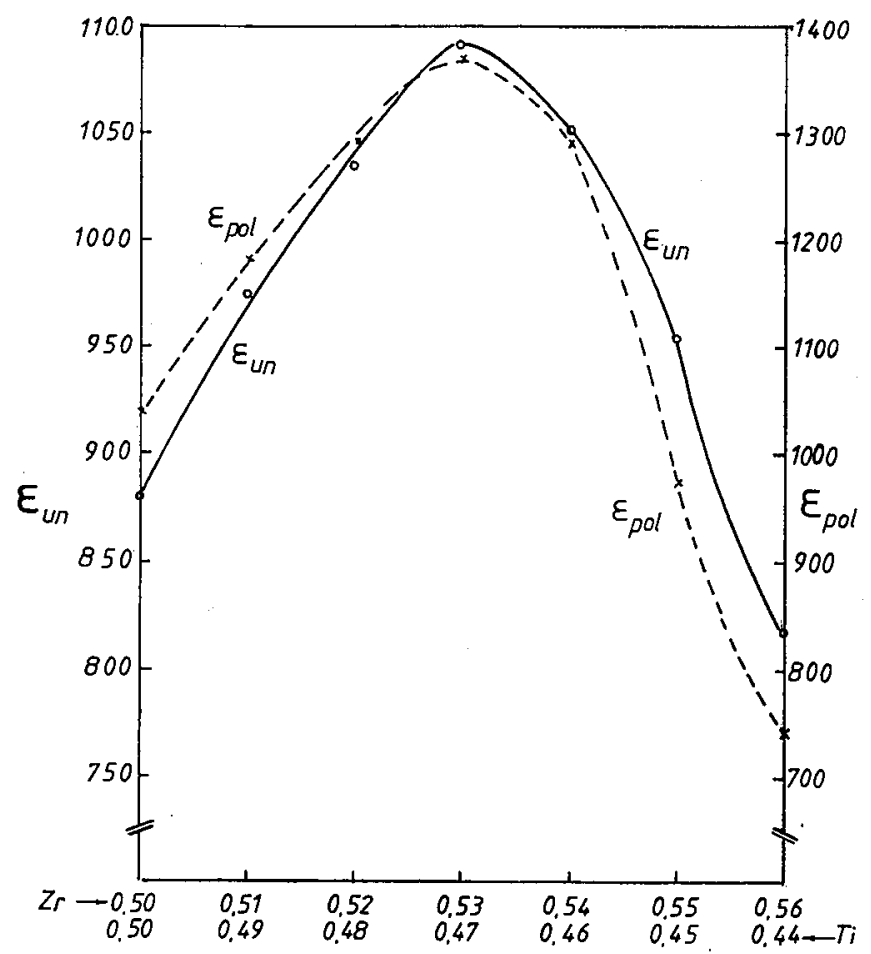

Fig. 4. Effect of $\mathrm{Zr} / \mathrm{Ti}$ ratio on the dielectric constant of polarized $\left(\epsilon_{\mathrm{pol}}\right)$ and unpolarized $\left(\varepsilon_{\mathrm{un}}\right) \mathrm{PZT}$ containing 1 wt \% niobium.

of $\mathrm{Ti}^{4+}$ ions. This caused the reduction of the dipole moment of the rhombohedral structure which decreased the dielectric constant.

In the tetragonal structure of PZT there are two types of domains, $180^{\circ}$ and $90^{\circ}$ domain rotations [1]. After the poling process, the $90^{\circ}$ domains referred to their original positions entirely leading to minimum strain. The lower strain explains the increase in the dipole moment of the polarized samples leading to higher dielectric constant than in the unpolarized sample. In the rhombohedral structure there are three types of domains, $180^{\circ}, 109^{\circ}$ and $71^{\circ}$ domains. The decrease in the dielectric constant of the polarized samples with respect to that of the unpolarized sample is assumed by some proportion of $109^{\circ}$ and $71^{\circ}$ domains remaining after the poling process. This type of domains increases the internal strain at the zirconium sites, leading to lowering of the dipole moment in the octahedral configuration. This behaviour explains the decrease of $\varepsilon_{\mathrm{pol}}$ with respect to the unpolarized one.

\section{Acknowledgement}

The authors express their thanks to Prof. Dr. A. Tawfik (Physics Department, Faculty of Science, Tanta University) for his cooperation and discussions during this work. 


\section{References}

[1] W.P. Mason, Physical Acoustics, Part A, Academic Press, New York, London 1964, p. 209.

[2] B. Jaffe, R. S. Roth, S. Marzullo, J. Res. Natl. Bur. Stand. (USA) 55, 239 (1955).

[3] R.B. Atkin, R.M. Fulrath, J. Am. Ceram. Soc. 54, 265 (1971).

[4] F. Kulcsar, J. Am. Ceram. Soc. 42,343 (1959).

[5] A. Tawfik, F. Abd El-Salam, Sprechsaal 113, 932 (1980).

[6] IRE Standards on Piezoelectric Crystals, Proc. IRE 49, 1162 (1961).

[7] A.H. Meitzler, H.M. O'Bryan, Jr., J. Am. Ceram. Soc. 55, 504 (1972).

[8] T. Iked, Y. Tanaka, T. Ayakawa, H. Noake, Jpn. J. Appl. Phys. 3, 581 (1964).

[9] R.B. Atkin, R.L. Holman, R.M. Fulrath, J. Am. Ceram. Soc. 54, 113 (1971).

[10] A. Tawfik, J. Am. Ceram. Soc. 68, 317 (1985).

[11] F. Abd El-Salam, A. Tawfik, A.I. Eatah, Sprechsaal 120, 192 (1987).

[12] A. Tawfik, M.M. Abou-Sekkina, M.K. El-Nimer, Indian J. Phys. A 52, 164 (1978). 